\title{
"CON SAL Y AJI Y TOMATES": LAS REDES TEXTUALES DE BERNAL DÍAZ EN EL CASO DE CHOLULA
}

POR

\author{
SARAH H. BeckJord \\ Columbia University
}

Al final de la Historia verdadera de la conquista de la Nueva España, Bernal Díaz del Castillo menciona en la larga lista de sus "Batallas y reencuentros": "La de Cholula, cuando nos quisieron matar y comer nuestros cuerpos, y que no la cuento por batalla" (661). ${ }^{1}$ Este juicio final sorprende, puesto que la representación del episodio que el conquistador ofrece en su obra exhibe todos los aspectos de un auténtico conflicto bélico.

Pero esto no es lo único que llama la atención de su texto. Dentro de las crónicas del período, la versión que el viejo soldado ofrece sobre los acontecimientos de Cholula se destaca por la vívida imagen del confrontamiento directo entre los españoles y los guerreros indígenas. Estos últimos están claramente representados en esos momentos no sólo como listos para combatir sino también como ansiosos por cometer los más sangrientos actos de barbarie y canibalismo en contra de los advenedizos españoles.

La inconsistencia de Bernal Díaz señala la naturaleza problemática del episodio de Cholula en el contexto de las tempranas crónicas de la Nueva España, sobre todo si se busca la "verdadera" historia de lo acontecido. Al examinar rigurosamente los sucesos de Cholula presentados por el viejo conquistador, surgen características que dejan al descubierto las intenciones de su texto y que señalan la necesidad de estudiarlo en relación con los escritos sobre el tema que lo preceden. Ya que, las deudas que contrajo con los cronistas anteriores son vitales para una comprensión más adecuada del designio que motivó su obra.

Por esta razón, para intentar entender los móviles que impulsaron la pluma de Bernal Díaz, es imprescindible una comparación de su recuento con los de las crónicas contemporáneas de Oviedo, Gómara y Las Casas, ${ }^{2}$ puesto que, todas ellas, manejando elementos comunes pero claves del suceso, difieren en el significado de lo relatado. Al

\footnotetext{
${ }^{1}$ Cita proveniente del manuscrito de Guatemala. Las posteriores citas de la Historia verdadera en este estudio pertenecen al manuscrito Remón. En este manuscrito, Bernal Díaz resume el suceso como "el peligro de lo de Cholula" (661). Ver cotejo de ambos manuscritos en la excelente edición crítica de Sáenz de Santa María. Para la información específica referente a los dos manuscritos, véase el estudio preliminar (xiii-xxxvii).

2 Iglesia ("Introducción"), Marcus, y Adorno ("Discourses") han señalado la batalla textual que Bernal Díaz sostuvo contra Las Casas.
} 
empezar ese examen, se evidencia la fuerte contienda textual que el viejo soldado sostiene en contra de propuestas planteadas por algunas de esas versiones. Asimismo, se percibe la existencia de la dualidad en la que se fundamenta la Historia verdadera: por un lado se observa el proyecto historiográfico del autor, inspirado tanto en sus lecturas de otros cronistas como en los hechos en los que había participado y que recordaba; por el otro, se advierten sus esfuerzos para responder a las cambiantes situaciones políticas y legales, de las cuales dependían sus posesiones de tierra en el Nuevo Mundo.

Pero antes de especificar estos aspectos, es necesario, con el fin de precisar algunos de los rasgos peculiares del texto de Bernal Díaz, hablar de los esfuerzos para delimitar aspectos que se relacionan con "historia" y "ficción" en los escritos coloniales hispanoamericanos. Con este propósito, Mignolo sugiere que ha habido

[...] un cambio epistemológico en el cual se consolidan la historia literaria y la historia de la historiografía y se recuperan, del pasado, aquellos textos que "muestran" desde la perspectiva de la recepción, ciertas propiedades o historiográficas o literarias, aunque estas propiedades no sean características en la producción de tales discursos (59).

Esta distinción entre el tiempo de producción y el de recepción ayuda a agudizar la sensibilidad de la crítica contemporánea hacia los textos coloniales, especialmente con respecto al reconocimiento de las convenciones retóricas e historiográficas en las que ellos se sustentan. Al mismo tiempo, revela las limitaciones de algunos acercamientos recientes, que intentan distinguir entre "historia" y "ficción" en los escritos del siglo XVI.

En esta última tendencia se encuentra el caso de Pastor, ${ }^{3}$ quien mediante la comparación de episodios claves entre las Cartas de relación de Cortés, la Historia verdadera y otros textos tanto indígenas como españoles, intenta identificar la "ficcionalización" que se halla en esos escritos; particularmente en los de Cortés y en menor grado en el de Bernal Díaz, cuyo relato Pastor percibe como más "verídico" (109) que los cortesianos (75-167). Cabe señalar, sin embargo, que entre las divergencias que ella menciona en el episodio de Cholula, está la acusación que hace Bernal Díaz de que los cholultecas fraguaban una conspiración para atrapar y cocinar a los españoles (134); situación que aparecía ya en las crónicas de Oviedo y Gómara.

Este préstamo que rutinariamente la crítica obvia, sea o no verdadero lo que se dice que aconteció, parece indicar que Bernal Díaz, al seguir tan de cerca el modelo ofrecido por cronistas "letrados", pensaba que escribía historia. Esta situación evidencia quizá el hecho de que el copiar circunstancias constituía una de las prácticas históriográficas normales en la época. De ahí que, al analizar textos de este tipo, deba examinarse también su intertextualidad. Además, con el fin de alcanzar una comprensión más precisa de ellos, también debe tenerse en cuenta que la tradición neoclásica de la historiografía asume la licencia de crear diálogos y descripciones apropiados para la ocasión (Nelson 4-5).

${ }^{3}$ Una versión diferente de esta tendencia se ilustra en el trabajo de Gilman, quien estudia "las islas familiares de estilo y referencia literaria" en la Historia verdadera (99). Todas las traducciones en esta investigación son nuestras. 
De igual manera, el aporte de otra tendencia crítica importante arroja luz sobre las intenciones textuales de la historiografia del siglo XVI. Los hallazgos de estos estudiosos se centran en las contiendas legales, cuyos principios e intenciones fueron vitales en la estructuración de muchos de los escritos coloniales. Sobre este aspecto, GonzálezEcheverría ha observado acertadamente que: "las batallas legales se desataron en todos los niveles durante la conquista de América, determinando la manera en la cual las historias del proceso se debían escribir" (114). El interés reciente en temas jurídicos recoge una larga tradición crítica. Diversas investigaciones, en su mayoría de naturaleza histórica ya en las décadas de 1930 y 1940, se enfocaron en los asuntos legales involucrados en la conquista. ${ }^{4}$ Del mismo modo, Frankl (1960) estableció las bases jurídicas e ideológicas de las Cartas de relación de Cortés en las Siete Partidas; mientras que Merrim (1986), siguiendo la misma dirección, amplió la investigación sobre la postura narrativa de este conquistador en sus cartas. Por su parte, Iglesia (1941) destacó el impacto que la controversia sobre la justificación de la guerra contra los indígenas americanos tuvo en los escritos historiográficos de las décadas de 1540 y 1550 , cuando el futuro de la encomienda como institución estaba en entredicho. ${ }^{5}$

Posteriormente, Adorno (1988) profundizó en el asunto especificando que la Historia verdadera representa un esfuerzo sistemático para impugnar no tanto la versión de Gómara, sobre la que Bernal se queja constantemente, sino la de Las Casas, quien era un adversario más inquietante para el viejo conquistador, dado el papel que el clérigo desempeñó en la controversia sobre la institución de la encomienda ("Discourses" 242). Específicamente, en su estudio sobre el episodio de Cholula, ${ }^{6}$ Adorno identifica los aspectos que se pueden leer en Bernal como correspondientes a la teoría de Sepúlveda sobre la Guerra Justa, los que le sirven al viejo soldado para impugnar la versión de Las Casas. Según Bernal Díaz, los españoles previnieron el exceso de saqueos por parte de sus aliados, establecieron la paz, libraron a prisioneros destinados al sacrificio y difundieron el catolicismo. Mientras que, la característica esencial de los bárbaros indígenas es el canibalismo ("Discourses" 246-247).

\footnotetext{
${ }^{4}$ En 1935, Zavala distinguió dos etapas mayores en la formulación teórica de los problemas jurídicos que se presentaron durante la conquista. En la primera, las incursiones españolas dentro del territorio americano se justificaron al extender a éste la jurisdicción y el valor de las instituciones occidentales, tales como la autoridad del Papa y del Emperador, mientras que los nativos americanos jurídicamente se tuvieron en inferior categoría (infieles, bárbaros, etc.) que los europeos. Estas ideas fueron modificadas posteriormente, en lo que Zavala considera una segunda etapa: cuando la autoridad europea sobre los indígenas se cuestionó, y se reafirmó la humanidad del hombre oriundo del Nuevo Mundo. Como resultado de este cambio de perspectiva, el concepto legal que se había establecido sobre "el bárbaro" varió y solamente se consideró la infidelidad religiosa como razón justificable para la conquista (Zavala 15-231).

5 "[...] fueron los intereses y los pleitos del Bernal Díaz encomendero lo que dieron origen en su forma primera al relato estupendo de las hazañas de Bernal Díaz y sus compañeros [...]. En la gigantesca polémica que originó el descubrimiento y la conquista de las Indias, la obra histórica de Bernal ocupa el polo opuesto a la de Las Casas. Defensa de los derechos del indio en éste, defensa de los derechos del conquistador en aquél" (Iglesia, "Introducción" 138).

${ }^{6}$ En el mismo artículo, Adorno también señala otros dos episodios que apoyan la tesis de que la escritura de Bernal Díaz está motivada por los pleitos y el debate de la guerra justa.
} 
Ahora bien, a otro nivel, las preocupaciones y las quejas en materias legales que expresa Bernal sobre los otros cronistas implican los esfuerzos que el viejo soldado hacía para estar al día sobre lo que se escribía con respecto a la conquista de México. Esta particularidad se sugiere en el pasaje tantas veces citado del capítulo XVIII de la Historia verdadera, que habla sobre el trabajo de Gómara e Illescas: "torné a leer y a mirar las razones y pláticas que el Gómara en sus libros escribió, e vi desde el principio y medio hasta el cabo no llevaba buena relación, y va muy contrario de lo que fue e pasó en la Nueva España" (34).

En este sentido, desde hace tiempo los críticos han reconocido la necesidad de un estudio comparativo de la Historia verdadera con otras crónicas del período. Iglesia, por ejemplo, asevera que "Gómara no sólo estimuló a Bernal sino que le sirvió de pauta en su relato" (35); Lewis encuentra que la caracterización y crítica bernaldiana del estilo de Gómara es injusta (47). Raymond Marcus, por otra parte, contrasta las diferentes versiones de los acontecimientos de Cholula escritas por Cortés, Bernal, Motolinía y Las Casas. No obstante, el artículo de Marcus, como muchos de los trabajos comparativos que han emprendido el cotejo de las diferentes versiones, es de naturaleza "histórica"; es decir, examina los actos y pormenores que difieren o concuerdan sustancialmente, pero sin considerar la intertextualidad en términos de lenguaje y estilo. ${ }^{7}$ De ahí que valga recordar el acierto de Pupo-Walker al indicar que, igual que otras crónicas de la época, la Historia de Bernal Díaz es una obra "nutrida de otras lecturas y en la que se destacan episodios de singular amplitud imaginativa" (33).

El presente estudio aspira a subsanar en parte la necesidad de llevar a cabo investigaciones que involucren los distintos aspectos que se han mencionado como parte integral de la escritura de los textos coloniales. Para la realización de este propósito, se efectuará un cotejo del conocido episodio de Cholula en los escritos de Cortés, Oviedo, Las Casas y Díaz del Castillo, enfocando el análisis tanto en la construcción intertextual como en las intenciones e implicaciones legales que en ella se sugieren; siguiendo en parte la misma tendencia investigativa adoptada por críticos como Iglesia y Adorno, entre otros. Además, con los resultados que arroje la anterior investigación se podrán elucidar algunas de las razones que impelieron a estos autores a elaborar episodios de tanta controversia histórica como el de Cholula.

Entre todas las divergencias de los relatos, el intentar rastrear al menos una de ellas, la presencia y función de las hamacas o redes que llevaban los indígenas, contribuye a explicar la ambigüedad central. Como se verá, en efecto, en las crónicas de Oviedo, Gómara, y Bernal Díaz, estos aparejos, que no están en el relato de Cortés, se ofrecen tanto como prueba de una supuesta traición, como de la barbarie y el canibalismo de los indígenas. En el relato de Las Casas, en cambio, son evidencia de su inocencia.

a) La segunda Carta de relación de Cortés ofrece la primera versión escrita sobre los sucesos acaecidos en Cholula, a la vez que parece ser la base de las subsecuentes interpretaciones sobre el asunto. De acuerdo a Cortés, los españoles y sus aliados

7 Véase especialmente su estudio del episodio en Bernal Díaz (201-208). Incluso la valiosa Introducción crítica a la "Historia verdadera" de Sáenz de Santamaría también se basa en el estudio de las diferencias substanciales de lo relatado, más que en el estilo. 
tlascaltecas fueron bien recibidos por los cholultecas, a pesar de los rumores que corrían sobre una posible conspiración en contra de los españoles. Inicialmente, los indígenas ofrecieron comida a los conquistadores, pero el buen tratamiento pronto degeneró. Después de confirmar sus sospechas sobre una posible conjura en contra de él y su gente, Cortés convocó a una reunión a los indígenas, apresó a los jefes y lanzó a sus soldados al ataque, matando a más de 3,000 cholultecas en un lapso de dos horas. El relato de Cortés es breve y contiene los elementos esenciales que serán problemáticos en las versiones posteriores: a raíz de un supuesto complot, el capitán paga el buen trato y la comida que ofrecen los indígenas con el secuestro de los líderes y la matanza. ${ }^{8}$

b) En su General y natural historia de las Indias (1535), ${ }^{9}$ Oviedo parece ser el primer historiador en hacer énfasis sobre el canibalismo de los cholultecas como supuesta prueba de su proyectada traición y de su barbarie. Para Oviedo, la bienvenida que reciben los españoles en Cholula es, al igual que en la versión de Cortés, generosa, y está acompañada de obsequios de comida y de "tamemes" (hombres de carga) que portan hamacas. Pero, según Oviedo, mientras que las tropas aztecas aguardan en las afueras de la ciudad, los cholultecas secretamente se preparan a efectuar la orden de Moctezuma, el tlatoni (emperador) mexicano, para atrapar a los invasores dentro de las hamacas y después servirlos como comida. Oviedo ilustra este momento con una conversación que escucha el traductor Aguilar de un grupo de tamemes. Escribe el cronista que los cholultecas no dejaron de

[...] acoger a los cristianos y darles muy bien de cenar aquella noche, a cada uno una gallina y tortillas de maíz; e otro día dijeron que si querían ir, les darían indios que llevasen las cargas, como lo hicieron. Alli vinieron mensajeros de Montezuma [...], y envióle [al señor de la ciudad] a mandar que atase los cristianos y se los llevase.

[...] salido el sol, vinieron indios para llevar las cargas de los cristianos, e los cristianos decíanles que trujesen de comer; e los indios, sonriéndose, decían entre sí: 'Para qué quieren comer éstos, pues presto que han de comer a ellos cocidos en aji.' E decían más; 'Si Montezuma no se enojase, aquí los mataríamos nosotros, e nos los comeríamos' [...]. E Cortés dijo que sería muy bueno castigar aquella ciudad, e mandó a los indios que trujesen hamacas para llevar a los cristianos principales, y ellos holgaron mucho de esto, porque pensaban atallos en las hamacas y entregallos en ellas a Montezuma (12-14).

Oviedo amplifica la descripción de Cortés sobre el complot, atribuyendo el buen trato al engaño y enfatizando no la sugerencia cortesiana de que los conquistadores tenían hambre, sino las ansias canibalescas de Moctezuma y los tamemes. En este punto debe observarse

\footnotetext{
${ }^{8}$ Como lo señaló Sáenz de Santa María, este episodio suscitó muchas riñas tanto textuales como legales, incluida la de Fray Francisco de Aguilar, quien escribió que Cortés hizo matar a los indios que cargaban agua y leña como castigo a otros que rehusaban hacerlo (Introducción 53). Véase también la mención que hace Gurría Lacroix de las declaraciones de Bernardino Vázquez de Tapia en un proceso contra Cortés, durante el cual aquél dijo que no sabía el por qué del castigo ya que el trato de los españoles en Cholula había sido acogedor (Vazquez de Tapia 38, nota 35).

${ }^{9}$ Para este análisis se ha empleado la edición preparada por O'Gorman, que antologiza las secciones que se relacionan con México, titulada Sucesos y diálogos de la Nueva España.
} 
que, puesto que Oviedo no presenció los hechos, el informe omnisciente que este cronista ofrece sobre la secreta conversación ("decían entre sí"), presumiblemente en un lenguaje que le costaba entender al traductor Aguilar, es ejemplo de la clase de recursos que se emplean en la historiografía renacentista para ilustrar un aspecto moral. En este caso, el cronista utiliza esta convención para mostrar la naturaleza diabólica y contra natura de los salvajes indígenas; característica que justificaría las acciones de los españoles en el Nuevo Mundo. ${ }^{10}$

c) Publicada en 1552, 17 años después de la obra de Oviedo y al año siguiente de haberse realizado el debate de Valladolid, se entiende que la exégesis de Gómara sobre Cholula en su Historia de la conquista de México, destaque aspectos relevantes en la controversia sobre la Guerra Justa, como es el de la perfidia y la traición de los indígenas, en oposición al correcto empleo del protocolo judicial que, según él, Cortés empleara en tales circunstancias. Los cholultecas están representados en este texto rehusando el desafío que les hizo Cortés para que cesaran de intrigar:

Ellos respondieron que eran sus amigos y servidores, y que lo serían siempre; y que ni le mentían ni le mentirían, sino que antes les dijese cuándo quería partir, para irle a servir y acompañar armados. [Cortés] les dijo que otro día, y que no quería más de algunos esclavos para llevar el fardaje, que venian ya cansados sus tamemes, y alguna cosa de comer. De esto postrero se sonreían, diciendo entre dientes: 'Para qué quieren comer éstos pues presto que les tienen de comer a ellos en ají cocidos, y si Moctezuma no se enojase, que los quiere para su plato, aquí los habríamos comido ya (194).

[...] Así que, otro día de mañana, y muy alegres, pensando que tenían bien entablado su juego, hicieron venir muchos para llevar el hato, y otros con hamacas para llevar a los españoles, como en andas, creyendo tomarlos en ellas. Vinieron a eso mismo cantidad de hombres armados, de los muy valientes, para matar al que se rebullese [...] (195).

La insistencia de Gómara sobre los engaños de los cholultecas establece la base de la traición indígena que motivó el posterior "castigo" ejecutado por los españoles. Este cronista yuxtapone este supuesto delito a la acusación de Oviedo sobre el canibalismo, que cita casi palabra por palabra; salvo para agregar que, a pesar de que Cortés sólo había pedido algunos pocos esclavos, los cholultecas habían traído muchos de ellos junto con otros guerreros armados. Como se observa en otro nivel, Gómara, fiel al modelo clásico, estructura su texto alrededor de un héroe (Frankl, Antijovio 88), y realza, como ya se hiciera antes, tanto el juicioso comportamiento de Cortés como el cobarde de los indígenas.

d) También publicada en 1552 (pero escrita diez años antes, durante los debates sobre las Nuevas Leyes), ${ }^{1}$ la Brevísima relación de la destrucción de las Indias de Las Casas reduce casi al mínimo el recuento sobre el suceso, aprovechando expertamente sus ambigüedades. La sección de la obra de Las Casas que se relaciona con la Nueva España comienza con el episodio de Cholula, que el fraile dominico califica como una "matanza o castigo" (103) injustamente infligido a los tamemes a pedido de Cortés:

\footnotetext{
${ }^{10}$ Véase la caracterización de Frankl sobre la obra de Oviedo como "naturalista y antihumanista" (Antijovio 87).

"Véase la descripción de Saint-Lu para las actividades políticas de Las Casas en ese tiempo, y para un estudio sobre la Brevíssima relación (122-125).
} 
Ver a estos indios cuando se aparejan para llevar las cargas de los españoles es haber dellos una gran compasión y lástima, porque vienen desnudos en cueros, solamente cubiertas sus verguienzas y con unas redecillas en el hombro con su pobre comida; pónense todos en cuclillas, como unos corderos muy mansos (104).

Las Casas incorpora la evidencia esencial de las versiones anteriores: la comida, los tamemes; pero esta vez no hay hamacas, sino unas redecillas. Lo que en Oviedo y Gómara era prueba del plan para matar y comer a los españoles, en Las Casas es por metonimia un cuadro de absoluta docilidad. Pues, textualmente invierte los signos de la representación de los habitantes, al pintar una imagen de indefensión por parte de los cholultecas. Este tipo de inversión es característica de la obra lascasiana, que expresa una visión "a la vez ética y pragmática" (Saint-Lu 125).

e) Escrita después de las otras versiones (y no publicada hasta 1632), la exégesis de Bernal Díaz sobre el mismo episodio es más extensa que las otras y parece intentar responder a todas ellas al mismo tiempo. En particular, refuta directamente la vaguedad que le permite a Las Casas ofrecer una historia tan diferente a partir de las mismas bases textuales:

[...] los guerreros que Montezuma envió estaban en unos ranchos y arcabuezos obra de media legua de Cholula [...] y otros estaban ya dentro en las casas, y todos puestos a punto con sus armas [...], y aun tenían en unas casas llenas de varas largas y colleras de cueros y cordeles con que nos habían de atar y llevarnos a México (158).

[...] e dijéronle [los cholultecas a Cortés] que sí darían asi los hombres de guerra como los del fardaje; e demandaron licencia para irse luego a los apercibir, y muy contentos se fueron, porque creyeron que con los guerreros que habían de dar e con las capitanías de Montezuma que estaban en los arcabuezos y barrancas, que allí de muertos o presos no podríamos escapar [...] (160)

[...] Y cuando amaneció era cosa de ver la prisa que traían los caciques y papas con los indios de guerra, con muchas risadas y muy contentos, como si ya nos tuvieron metidos en el garlito y redes [...] (162) [énfasis en el original].

Aquí, en lugar de las ambiguas hamacas mencionadas por Oviedo y Gómara, o de las redecillas de Las Casas, se encuentran "varas largas y colleras de cueros y cordeles" y "el garlito y redes" para atar a los españoles, voces que en la época tenían connotaciones punitivas. ${ }^{12}$ De esta forma, el viejo conquistador acentúa tanto la atmósfera de guerra y

\footnotetext{
${ }^{12}$ Entre las acepciones de la época, "varas" significa "unos manojos con que açotavan los delinquentes o esclavos [...]. Algunas destas varas llamaban sanguíneas, por dar con ellos açotes de muerte" (Cobarrubias 994). "Colleras": "la cadena de forzados ò presidarios, que se conducen à las galeras, o presidios" (Autoridades I, 417). "Cordel”: "Apretar los cordeles, necesitar a uno a que confiese lo que le está bien negar. Tomóse la metáfora de los cordeles que aprietan a los que ponen a quistión de tormento. [....] [E]char el cordel, guardar justicia y sea contra quien se fuere. Está tomado de los ediles y juezes de policía, que para sacar una calle derecha, que vaya a dar a palacio, a plaça, o a otro
} 
de peligro que se vivía, ya no sólo en las afueras, sino dentro de Cholula, como el canibalismo de los naturales. Y en lugar de la difícilmente comprobable conversación "secreta" de los indígenas en las versiones de Oviedo y Gómara, Bernal Díaz trasmite la acusación en un discurso indirecto en el cual Cortés se dirige a los cholultecas: "que pues en pago de que los venían a tener por hermanos e decirles lo que Dios nuestro señor y el rey manda, nos querían matar y comer nuestras carnes, que ya tenían aparejadas las ollas con sal y ají y tomates" (163). De esta forma, según Bernal, luego de ser confrontados con la evidencia concreta de su traición, los principales cholultecas confiesan el delito, y culpan a Moctezuma.

Bernal Díaz vuelve al tema de las redes al cerrar el relato de Cholula, cuando recuerda a los presos destinados al sacrificio, que liberaron los españoles:

Y no puedo dejar de traer aquí a la memoria las redes de maderos gruesos que en ella hallamos; las cuales tenían llenas de indios y muchachos a cebo, para sacrificar y comer sus carnes, las cuales redes quebramos, y los indios que en ellas estaban presos les mandó Cortés que se fuesen adonde eran naturales [...] (166).

Es decir, además de las inconfundibles implementos destinados para atrapar a los cristianos, Bernal Díaz incluye otras "gruesas" redes, en las cuales los cholultecas tenían cautivos y engordando a sus inocentes víctimas. Como se observa, en este contexto el uso de la voz "redes" que emplea el viejo conquistador no es casual, puesto que enseguida refuta directamente la versión de Cholula del Obispo de Chiapas: "[...] porque afirma y dice que sin causa ninguna, sino por nuestro pasatiempo y porque se nos antojó, se hizo aquel castigo $[. . .]^{\prime \prime}(166) .^{13}$

Asimismo, en el relato de Bernal Díaz se halla, de manera amplificada y modificada del de Gómara, tanto el desafio que hace Cortés para librar una batalla en campo abierto y el rumor de que los españoles habían sido avisados de no ir a Tenochtitlán a causa de la ira de Moctezuma sobre hechos ocurridos en Cholula, como el peligro que corrían de pasar a ser refrigerio del antropófago tlatoni:

Y supimos muy de cierto que cuando lo supo Montezuma que sintió gran dolor y enojo [...] y aun supimos que estuvo encerrado en sus devociones y sacrificios dos días [...] y que hubo respuesta de aquellos ídolos, y fue que le aconsejaron que nos enviase

lugar público, echan su cordel y todo lo que cae dentro dél lo derriban, tassando primero lo que se ha de recompensar a sus dueños, sin respetar a nadie" (Cobarruvias 357). "Garlito": "celada, lazo d assechanza, que se arma a alguno para molestarle y hacerle daño" (Autoridades I, 27). "Red": "para pescar y cazar. [...] qualquier texido hecho en la misma forma [...] para varios usos. [...] Llaman tambien à un género de prisión, que tienen en los Lugares pequeños. [...] Metaphoricamente vale ardid ò engaño ..." (Autoridades III, 528). Para ver las otras acepciones del momento, consúltense las obras citadas.

${ }^{13}$ Fragmento citado por Adorno, quien aclara que la reprobación de Bernal Díaz es injusta, ya que Las Casas no había acusado a los españoles de matar "por pasatiempo", sino por haber hecho un castigo ejemplar ("Discourses" 248). 
mensajeros a disculpar de lo de Cholula, y que con muestras de paz nos deje entrar en México, y estando dentro [...] nos matarían [...]. Y tendrían hartazgos de nuestros muslos y piernas y brazos; y las tripas y el cuerpo y todo lo demás hartarían las culebras y sierpes y tigres que tenían en unas casas de madera [...] (166).

Con esta mórbida insistencia no sólo en detalles espantosos, sino en la repetición de la idea de los hartazgos, Bernal Díaz vuelve la imagen de Gómara más gráfica, mientras que destaca la naturaleza bestial de los indígenas. Los cambios temporales que efectúa el conquistador del pasado al presente ("nos deje") y al condicional ("tendrían", "hartarían") son una característica de su obra. Al trabajar a partir de los textos de sus contemporáneos, Bernal Díaz suple los vacíos de información con sus memorias y con su imaginación. ${ }^{14}$ De ahí que la reconstrucción de las glorias pasadas que efectúa involucra giros imaginativos, tales como en este caso, el de penetrar los pensamientos del tlatoni de los aztecas y anticipar hechos que nunca ocurrieron. ${ }^{15}$

Como se observa, estas supuestas inconsistencias se deben no sólo al esfuerzo de recrear memorias lejanas, sino también a las técnicas composicionales y legales del momento histórico que le sirven a Bernal para estructurar la defensa de las acciones de los conquistadores en el Nuevo Mundo. Alegato que de ser aceptado, le ayudaría a apoyar mejor sus reclamos legales o a conservar tanto las propiedades como las prebendas adquiridas en su calidad de conquistador.

El hecho de que el episodio de Cholula se muestre como uno de los más contenciosos en los recuentos del siglo XVI sobre la conquista de la Nueva España en las disputas legales del momento (Adorno, "Discourses" 246), tal vez explique el cuidado con el que los diferentes autores recomponen la misma evidencia textual para construir casos sustancialmente diferentes, a la vez que indica la importancia que todos ellos le concedieron como recurso persuasivo en la contienda escrita en la que tomaban parte.

Como ya se ha señalado, la batalla librada por estos autores se centra en la esencia de la controversia de la Guerra Justa, como la debatieron Las Casas y Sepúlveda. ${ }^{16}$ El principio legal que se examinó fue el de la Ley Natural, ${ }^{17}$ y se puso en entredicho la justificación de la conquista y la subyugación de los recién descubiertos territorios.

Este debate, como lo notó O'Gorman, involucró a "todos los más eminentes representantes de la intelectualidad española de la época" ("Naturaleza" 144), y giró en torno al problema de la índole de los indígenas americanos, derivada, a su vez, de la observación de su conducta y de sus civilizaciones. Para afirmar que la conquista era

\footnotetext{
${ }^{14}$ En este sentido, Cortínez anota la discordia en el "yo" narrativo de la Historia verdadera, y "la incapacidad del narrador de mantenerse fiel a una sola perspectiva" (67).

${ }^{15}$ Para una discusión de este tipo de discurso que polemiza con la verosimilitud, véase MartínezBonati (10-13).

${ }^{16}$ Para un resumen del contexto y la sustancia de este debate, véase Hanke, 1974.

${ }^{17}$ La doctrina clásica de la Ley Natural asume básicamente que toda dominación es un fenómeno natural y extenso, un principio de organización y también un "bien" social. Para la expresión de esta teoría en la polémica americana del siglo XVI, véanse: O'Gorman ("Naturaleza") y Pagden (Caida y "Preservation").
} 
justa, Sepúlveda combinó la teoría de la Ley Natural (la única que tenía jurisdicción sobre los extranjeros que no eran cristianos) con las leyes del Viejo Testamento, y citó el Deuteronomio y el Levítico como precedentes de que Dios había castigado a las tribus "bárbaras" y "pecadoras" con guerras y destrucciones por haber rechazado la fe cristiana, por haber adorado ídolos y por haber realizado sacrificios humanos (44). ${ }^{18}$ Desde su punto de vista, todo esto autorizaba a los españoles a que efectuaran la guerra y confiscaran propiedades de los indígenas. Pues, como viciosos caníbales, los naturales americanos estaban tan lejos de alcanzar la salvación que merecían la muerte, aunque en este caso, no a manos de Dios sino de los conquistadores.

Central a la argumentación de Sepúlveda era la comparación de los indígenas americanos con los bárbaros europeos. Como González-Rodríguez ha observado, la idea de Roma "está en la médula de la gran polémica del Nuevo Mundo" (149). En Demócrates Segundo, Sepúlveda afirma que los griegos y romanos de la edad clásica siguieron la Ley Natural y por tanto eran dignos de salvación. Apoyándose en la autoridad de Santo Tomás y de San Pablo, también arguyó que, incluso los que habían vivido antes de Cristo y que habían creído en Dios y en la Providencia, habían de hecho intuido la presencia de Cristo y por tanto podían haberse salvado (Sepúlveda 53-54). Es decir, tanto los paganos de la antigüedad, como los profetas del Viejo Testamento, eran cristianos avant la lettre; los indígenas americanos, por el contrario, cometían crímenes contra la naturaleza y por esa razón eran claramente "siervos, bárbaros, incultos e inhumanos" (84).

Las Casas rebatió esa postura, defendiendo las civilizaciones indígenas al notar que todas las culturas poseían orígenes bárbaros y recordando los excesos del imperio romano y de su cultura. También aseveró que los que merecían la excomunión y el subsecuente castigo no eran los nativos sino los conquistadores, por el salvaje trato que les daban al indígena, "verdadero cordero" de Dios.

Una discusión a fondo de los orígenes de esta polémica y sus repercusiones en las tempranas crónicas de Indias queda fuera del alcance de este trabajo; sin embargo, cabe señalar un aspecto que arroja luz sobre las antecendentes textuales que hemos venido señalando del supuesto canibalismo y la barbarie de los indígenas, particularmente en Moctezuma.

En la Segunda carta de relación, Cortés presenta al tlatoni azteca como un tirano infiel, caracterizándolo estratégicamente ya como un rey magnífico, ya como un ser disipado e incapaz (Merrim 66). En las obras de Oviedo y Gómara, Moctezuma llega a ser caníbal, representación que recoje las resonancias clásicas de la idea del tirano de un estado injusto en la República de Platón. El tirano platónico (también "bárbaro") comete, despierto y consciente, los excesos y abominaciones que sólo se desatan en el alma del hombre racional cuando está dormido:

\footnotetext{
${ }^{18}$ Véase Sepúlveda: "Testimonios y juicios de Dios son estos tantos y tan importantes que no dejan lugar a dudas a los hombres piadosos de que estos dos crímenes, el culto a los ídolos y las inmolaciones humanas, que consta eran familiares a esos bárbaros, justísimamente son castigados con la muerte de quienes los cometieron y con la privación de sus bienes, ya se trate de fieles como antes eran los Hebreos, ya de paganos, tanto antes como después de la venida de Cristo" (42).
} 
[...] no hay cosa a que no se atreva el alma, como si se hubiera emancipado violentamente de las leyes del decoro y del pudor; no distingue nada, ni dios, ni hombre, ni bestia; ningún crimen, ningún alimento indigno la horrorizan. En una palabra: que no hay acto, por extravagante, por infame que sea, a que no se arroje (Libro IX 587; también citado por Grene 10).

Al empeño de Oviedo y Gómara en retratar al tlatoni como tirano bárbaro y caníbal, responde Las Casas en su Historia general de las Indias, y en menor grado, en la Brevísima relación, con un giro no menos hábil que el que vimos en Cholula. Para éste, la tiranía de Moctezuma es menor que la de Cortés, cuya conquista política del imperio azteca logra destruir el sistema legal, la recolección de impuestos, y todas las demás funciones administrativas de las que dependen cualquier gobierno. A su vez, Bernal Díaz logra integrar las versiones opuestas al diluir tanto la imagen de Cortés (incapaz de tomar decisiones claves como la de apresar al emperador), como la de Moctezuma (caníbal, pero reformado y finalmente amigo de Bernal Díaz y otros conquistadores), y al mismo tiempo enfatiza la conducta cristiana de los españoles.

Como se ha visto, el tratar de distinguir críticamente entre lo histórico y lo imaginario en textos como la Historia verdadera es transitar por un campo minado, dadas las convenciones renacentistas de la historiografia, las intenciones del texto, y la contenciosa atmósfera en la que ellos fueron escritos. Además de la supuestamente "inventada" cocción con ají, se podrían examinar otros aspectos que la crítica ha señalado como muestra de la capacidad literaria o imaginativa de Bernal Díaz, como las referencias a los libros de caballerías, las cuales también se encuentran, aunque de manera indirecta, en las obras de Oviedo y Gómara.

Lo anterior no quiere decir que Bernal carezca de originalidad o de interés para el crítico moderno, ni que los aspectos destacados aquí sean los únicos fines que persigue el autor al escribir su historia; sino simplemente que se debe recordar la importante distinción que hizo Mignolo sobre el propósito del texto en el momento en que se escribió y la subsecuente recepción que interpreta el texto como ficticio. Por otro lado, se hace pertinente distinguir entre las intenciones jurídicas del caso textual de Bernal Díaz y aquéllas que constituyen lo que Jolles ha descrito como un "caso" literario. Para éste, el caso literario tiene la particularidad de plantear una pregunta, y no dar la respuesta definitiva, dejándole así al lector la necesidad de juzgar por sí mismo. El caso literario es “el lugar donde se realiza el equilibrio y la vacilación del estado mental que sopesa las opciones [...]" (151).

Es decir, autodidacta en materias legales, ${ }^{19}$ Bernal Díaz, quien había luchado diversas batallas para asegurar su propiedad y la herencia de sus hijos, no quiso dejar posibilidades abiertas para que se cuestionaran acontecimientos claves como los de Cholula. Al contrario de textos ficcionales o imaginativos, que existen independientemente de querellas reales sobre calumnias y recompensas, la Historia verdadera intenta aclarar entre un laberinto de versiones el contenido y el significado de las acciones de los conquistadores. En este

\footnotetext{
${ }^{19}$ Para información biográfica sobre los pleitos legales de Bernal y la documentación de su "probanza de méritos", véase Sáenz de Santa María (Introducción 79-86).
} 
sentido, aunque se puede estar de acuerdo con la observación de Hayden White de que las narraciones históricas emplean muchas de las mismas técnicas de la ficción (como también lo hacen las argumentaciones legales), esto no las convierte en ficciones literarias, ya que su razón de ser (y su mejor comprensión para el lector actual) está firmemente arraigada en circunstancias y textos de su época.

El episodio de Cholula indica tanto el aspecto altamente contencioso de las crónicas, como la magnitud de los problemas textuales e historiográficos que ellas presentan. Efectivamente, las crónicas de la conquista de México están cribadas por intrincados ataques y defensas que se relacionan con testigos, fuentes, estilo, y con la autoridad de los escritores como historiadores. El relato de Bernal Díaz en muchos aspectos está prefigurado por aquéllos en los que él se basó y a quienes responde. Al mismo tiempo, no sólo demuestra una compleja red de relaciones textuales con los escritos de sus contemporáneos, sino que señala el poder de la palabra escrita al establecer la historia de la conquista.

\section{Textos primarios}

\section{OBRAS CITADAS}

Casas, Bartolomé de las. Brevisima relación de la destrucción de las Indias (1552). Madrid: Cátedra, 1984. 1951.

Cobarruvias Orozco, Sebastián de. Tesoro de la lengua castellana o española (1610). Madrid: Turner, 1979.

Cortés, Hernán. Cartas de Relación de la conquista de México. Madrid: Austral, 1982. Díaz del Castillo, Bernal. La historia verdadera de la conquista de la Nueva España (1632). C. Sáenz de Santa María, editor. Madrid: Instituto González de Oviedo, 1982.

Fernández de Oviedo, Gonzalo. Sucesos y diálogos de la Nueva España (1535). México: UNAM, 1946.

López de Gómara, Francisco. Historia de la conquista de México (1552). México: Editorial Pedro Robredo, 1943.

Platón. La república. Sin traductor. Medellín: Bedout, 1986.

Sepúlveda, J. G. Demócrates Segundo (1780). A. Losada, traductor y editor. Madrid: Consejo Superior de Investigaciones Científicas, 1951.

Real Academia Española. Diccionario de autoridades (1737). 3 Volúmenes. Madrid: Gredos, 1963.

\section{Textos secundarios}

Adorno, Rolena. "Discourses on Colonialism: Bernal Díaz, Las Casas, and the Twentieth Century Reader". MLN 103.2 (1988): 239-258.

"The Discursive Encounter of Spain and America: The Authority of Eyewitness Testimony in the Writing of History". The William and Mary Quarterly 3rd. series, XLIX (1992): 210-228. 
Alvar, Manuel. "Bernal Díaz del Castillo". Historia de la literatura hispanoamericana Tomo I: Epoca colonial. Luis Iñigo-Madrigal, coordinador. Madrid: Cátedra, 1982. 127-134.

Cortínez, Verónica. “'Yo, Bernal Díaz del Castillo’: ¿Soldado de a pie o idiota sin letras?". Revista Chilena de Literatura 41 (1992): 59-69.

Frankl, Victor. El "Antijovio" de Gonzalo Jiménez de Quesada y las concepciones de realidad y verdad en la época de la contrarreforma y del manierismo. Madrid: Ediciones Cultura Hispánica, 1963.

"Hernán Cortés y la tradición de las Siete Partidas". Revista de historia de América 53-54 (1962): 9-74.

Gilman, Stephen. "Bernal Díaz del Castillo and 'Amadís de Gaula"'. Studia Philologica II (Homenaje a Dámaso Alonso). Madrid: Gredos, 1961. 99-114.

González-Echevarría, Roberto. "The Law of the Letter". Yale Journal of Criticism 1.1 (Fall, 1987): 107-133.

González Rodríguez, Jaime. La idea de Roma en la historiografia indiana. Madrid: CSIC, 1981.

Grene, David. "Introduction", The History by Herodotus. D. Grene, traductor. Chicago: University of Chicago Press, 1987. 1-32.

Hanke, L. All Mankind is One. Dekalb: University of Illinois Press, 1974.

Iglesia, Ramón. "Introducción al estudio de Bernal Díaz del Castillo y de su Verdadera Historia". Filosofia y Letras 1 (1941): 127-140.

"Las críticas de Bernal Díaz del Castillo a la 'Historia de la conquista de México' de Francisco López de Gómara”. Revista Tiempo X (1940): 23-38.

Jolles, Andre. Les Formes simples (1930). Traduit par Antoine Marie Buguet. Paris: Seuil, 1972.

Lewis, Robert E. "Retórica y verdad: los cargos de Bernal Díaz a López de Gómara". Merlin H. Forster y Julio Ortega, editores. De la crónica a la nueva narrativa mexicana. Oaxaca: Oasis, 1986. 37-47.

Marcus, Raymond. "La conquête de Cholula: conflit d'interprétations". IberoAmerikanisches Archiv (Neue Folge) 3.2 (1977): 193-213.

Martínez-Bonati, Félix. "El sistema del discurso y la evolución de las formas narrativas". Dispositio V-VI.15-16 (1981): 1-18.

Mignolo, Walter. "Cartas, crónicas y relaciones del descubrimiento y la conquista". Historia de la literatura hispanoamericana Tomo I: Epoca colonial. Luis IñigoMadrigal, coordinador. Madrid: Cátedra, 1982. 57-116.

Nelson, William. Fact or Fiction: The Dilemma of the Renaissance Storyteller. Cambridge: Harvard University Press, 1973.

O’Gorman, Edmundo. Cuatro historiadores de Indias (1972). $2^{\mathrm{a}}$ edición. México: Editorial Patria, 1989.

"Sobre la naturaleza bestial del indio americano". Filosofia y Letras 1 (1941): 141-158.

Pagden, A. La caida del hombre: El indio americano y los orígenes de la etnología comparativa. Madrid: Alianza, 1988. 
"The Preservation of Order: The School of Salamanca and the "Ius Naturae". Medieval and Renaissance Studies in Spanish and Portuguese in Honour of P.F. Russell, editor F. W. Hodcroft (et. al.). Oxford: Society of the Study of Medieval Languages and Literatures, 1989. 155-166.

Pastor, Beatriz. Discursos narrativos de la conquista de América. Hanover: Ediciones del Norte, 1988.

Pupo-Walker, Enrique. "Creatividad y paradojas formales en las crónicas mexicanas de los siglos XVI y XVII". Merlin H. Forster y Julio Ortega, editores. De la crónica a la nueva narrativa mexicana. Oaxaca: Oasis, 1986. 29-36.

Sáenz de Santa María, Carmelo. Introducción crítica a la "Historia verdadera" de Bernal Díaz del Castillo. Madrid: CSIC, 1967.

Saint-Lu, André, "Fray Bartolomé de las Casas". Historia de la literatura hispanoamericana Tomo I: Epoca colonial. Luis Inigo-Madrigal, coordinador. Madrid: Cátedra, 1982. 117-125.

White, Hayden. Tropics of Discourse: Essays in Cultural Criticism. Baltimore: Johns Hopkins University Press, 1978.

Zavala, Silvio A. Las instituciones jurídicas en la conquista de América (1935). Segunda edición aumentada y revisada. México: Porrúa, 1971. 